\title{
Rectocutaneous fistula with imperforate anus in an adult
}

\author{
Kazım Duman ${ }^{1}$, MD, Yavuz Ozdemir ${ }^{2}$, MD, Cengizhan Yigitler ${ }^{2}$, MD, Bülent Gulec ${ }^{2}$, MD
}

\begin{abstract}
Adult presentation of a rectocutaneous fistula with imperforate anus is rare. We report the case of a 22-year-old man who presented with an anorectal malformation and a rectocutaneous fistula. The patient complained of faecal matter passing through the external orifis of a fistula located at the distal part of his scrotum. He was continent for solid faeces, but had leakage of flatus and faecal soiling. He had no other associated anomaly. The patient subsequently underwent a surgical procedure where anal transposition was done. Postoperative recovery was uneventful, and the patient was fully continent at control examination.
\end{abstract}

Keywords: adult, imperforate anus, rectocutaneous fistula

\section{INTRODUCTION}

The incidence of anorectal malformations in newborns has been reported to be 1 in 4000 live births. (1) Patients affected by this disorder often have accompanying pathologies in other systems, such as the urinary system. Although anorectal malformation is easily diagnosed at birth with inspection, some difficulties may arise due to possible differential diagnoses. Surgical treatment differs according to the different anatomic variations of the malformation and its association with a variety of special syndromes and diseases. ${ }^{(2,3)}$

Although antenatal suspicions of imperforate anus have been reported, it is usually diagnosed only after birth. ${ }^{(4)}$ It is thought to be the result of developmental defects during embryologic life. To treat this malformation, knowledge of the associated structures - the anal canal, pelvic floor muscles and sphincter - is important. The treatment strategy varies according to the level and type of malformation, as well as the gender of the patient. ${ }^{(5)}$ In this report, we present the case of a rectocutaneous fistula with imperforate anus in a male adult.

\section{CASE REPORT}

A 22-year-old man who presented with gas and liquid stool incontinence was admitted to our department. Physical examination revealed an imperforate anus and an external fistula orifice, with faecal soiling, located at the distal part of the scrotum (Fig. 1). According to the patient, stool had been passed via this fistula. Apart from this, the patient was asymptomatic. Ultrasonography and other imaging modalities revealed no other system pathologies. Magnetic resonance (MR) imaging of the pelvic area showed a blind-ending rectal pouch and a rectocutaneous fistula running from the rectum to the scrotal skin at the level of the root of the penis. The external sphincter and levator ani muscles were intact.

The patient underwent surgery in the Lloyd-Davis position. A midline incision was made between the perineum and scrotum.

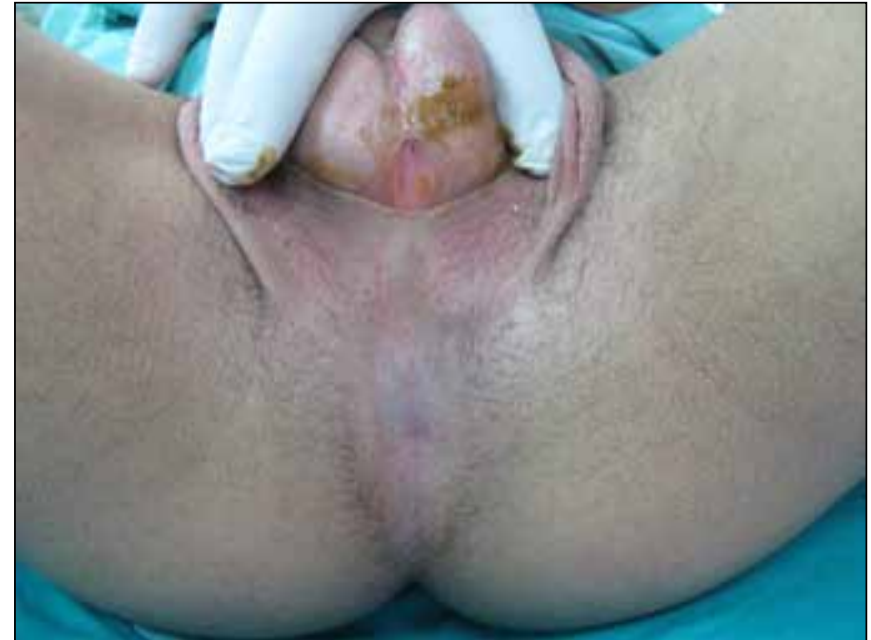

Fig. 1 Photograph shows the imperforate anus and external fistula orifice, with faecal soiling, located at distal part of the scrotum.

The fistula tract was dissected circumferentially to reach the blind-ending rectal pouch. The perineal layers and connection to the rectum were fully exposed. The rectum was freed circumferentially and transposed (Fig. 2a). Muscular structures were repaired layer by layer (Fig. 2b), and the operation was terminated without a diverting stoma. The patient was discharged uneventfully on postoperative Day 17 . Two months post surgery, he was fully continent and had no perianal problems (Fig. 3). Control evaluation, consisting of digital examination and anoscopy of the rectum, was normal. According to the Cleveland Clinic Incontinence Score (CCIS), the patient had good continence (score 6).

\section{DISCUSSION}

According to the Wingspread classification, imperforated ani can be divided into three types based on the distance between the blind-ended rectal pouch and anus. The line between the pubis

${ }^{1}$ Department of General Surgery, Gumussuyu Military Hospital, ${ }^{2}$ Department of General Surgery, GATA Haydarpasa Training Hospital, Istanbul, Turkey Correspondence: Dr. Yavuz Ozdemir, General Surgery Specialist, Department of General Surgery, Gulhane Military Medical Academy, Haydarpasa Training Hospital, 34668, Uskudar, Istanbul. Turkey. dryozdemir@yahoo.com 

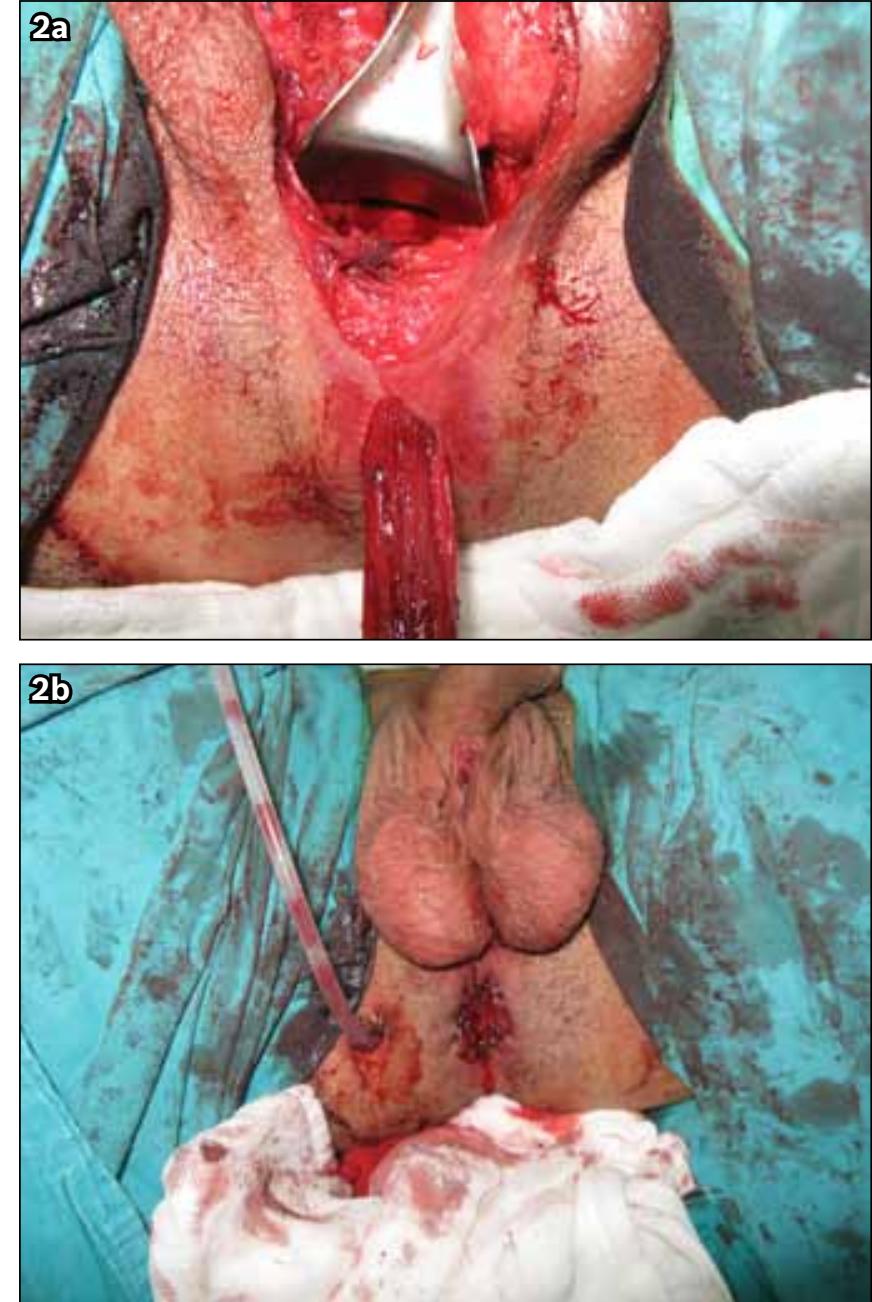

Fig. 2 Photograph shows (a) the anal transposition procedure being carried out, and (b) the view after anal transposition was completed.

and coccyx in an invertogram is called the pubococcygeal (PC) line. If the level of the blind end of the rectal pouch is above the PC line, it is classified as high-type imperforate anus; and if it is under this line, it is classified as low-type. All three types have perianal, rectovesical, rectourethral and rectovestibular forms, and can occur with or without fistulas. ${ }^{(6)}$ The level of the blind end is important, as it determines the choice of surgery and the patient's prognosis.

Posterior sagittal anorectoplasty (PSARP) with or without colostomy, described by Pena et $\mathrm{al}^{(7)}$ in 1982, is the most common surgical procedure for the correction of an imperforate anus. PSARP can also be performed using an anterior approach. Geargason et $\mathrm{al}^{(8)}$ described a laparoscopic approach in 2000. In our case, we chose to perform an anal transposition procedure using a perianal approach because of its tolerability and lower morbidity. There are a few case reports on imperforate anus in adults that have been treated using a method similar to ours (i.e. non-colostomy anal transposition), without complications. ${ }^{(9)}$

Hundreds of symptoms and pathologies accompanying imperforate anus have been reported in the literature, and these have an effect on the treatment strategy as well as prognosis..$^{(2,3)}$ In patients with a late prognosis, abdominal distension and lung problems have been reported in the literature. ${ }^{(10)}$ Rinata et $\mathrm{al}^{(11)}$

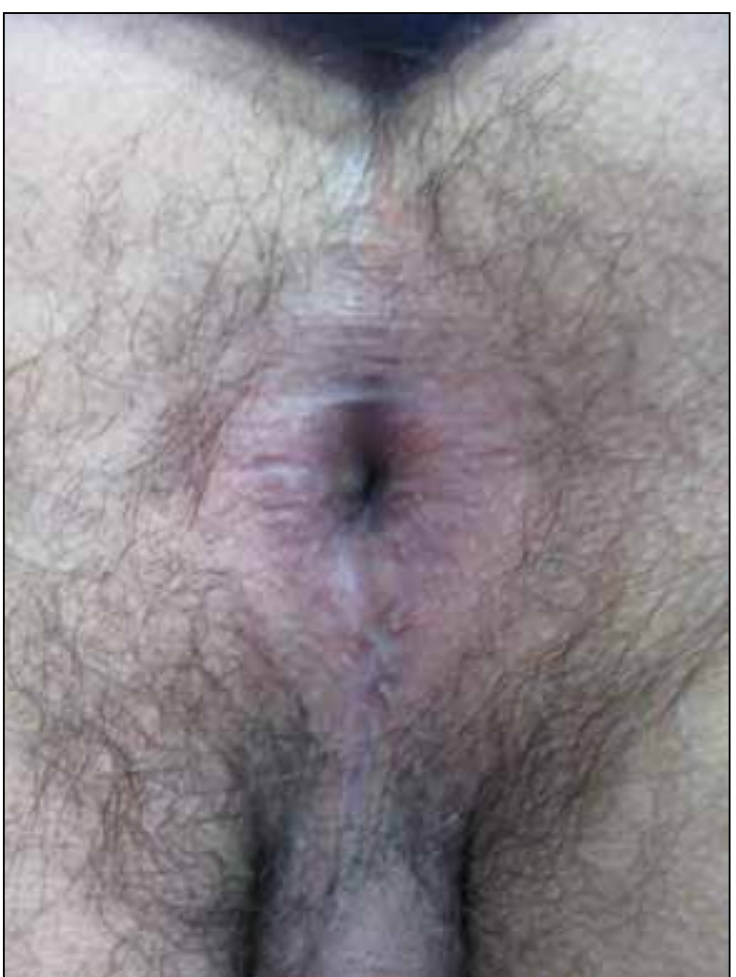

Fig. 3 Photograph of the anus at postoperative control examination, two months post surgery.

showed that $42.6 \%$ of patients who received a late diagnosis encountered other system anomalies. In our case, the fistula tract from the rectum to the scrotum worked as an anal canal, and thus, our patient remained asymptomatic and had no other pathologies.

The need for a colostomy may arise if megarectum occurs. In our case, however, megarectum did not occur, as there was faecal discharge through the fistula. Therefore, we did not choose colostomy even though it is preferred in acute-type patients. As colostomy was not performed, no complications or incontinence occurred as a result of it. Eltayeb ${ }^{(12)}$ reported delayed presentation in 20 out of 104 patients with anorectal malformations, which could lead to megarectum or a dilated colon, and the eventual need for a colostomy.

While our patient had not encountered any problems until the age of 21, there have been reports of patients presenting with sepsis and bowel perforations four days after birth. ${ }^{(13)}$ Therefore, it is recommended that a newborn be evaluated for physical defects, with perineal examination being conducted within the first day after birth. ${ }^{(14)}$ Diagnosis 48 hours after birth has been accepted to be late diagnosis, and in $13 \%$ of the patients reported in the literature, diagnosis was made after 48 hours. ${ }^{(15)}$ In Turkey, perineal examinations are performed soon after birth and continued at mother-child health centres. Unfortunately, the exact number of imperforate ani detected at an advanced age in Turkey is not known.

In conclusion, patients presenting with adult-type imperforate anus requires extensive tests and examinations. Complete pathology testing must be conducted and colostomy should be avoided, if possible. 


\section{REFERENCES}

1. Spouge D, Baird PA. Imperforate anus in 700,000 consecutive liveborn infants. Am J Med Genet Suppl 1986; 2:151-61.

2. Walters D, Burjonrappa S, Chun K. Imperforate anus, diaphragmatic hernia, horseshoe kidney, and pulmonary sling complex: case description. J Pediatr Surg 2011; 46:e5-7.

3. Solomon BD, Raam MS, Pineda-Alvarez DE. Analysis of genitourinary anomalies in patients with VACTERL (Vertebral anomalies, Anal atresia, Cardiac malformations, Tracheo-Esophageal fistula, Renal anomalies, Limb abnormalities) association. Congenit Anom (Kyoto) 2011; 51:87-91.

4. Lam YH, Shek T, Tang MH. Sonographic features of anal atresia at 12 weeks. Ultrasound Obstet Gynecol 2002; 19:523-4.

5. Fedele L, Bianchi S, Frontino G, et al. Laparoscopic findings and pelvic anatomy in Mayer-Rokitansky-Küster-Hauser syndrome. Obstet Gynecol 2007; 109:1111-5.

6. Aziz MA, Banu T, Prasad R, Khan AR. Primary anterior sagittal anorectoplasty for rectovestibular fistula. Asian J Surg 2006; 29:22-4.

7. Penã A, Hong A. Advances in the management of anorectal malformations. Am J Surg 2000; 180:370-6.
8. Georgeson KE, Inge TH, Albanese CT. Laparoscopically assisted anorectal pull-through for high imperforate anus--a new technique. J Pediatr Surg 2000; 35:927-30.

9. Terzi A, Coşkun A, Yıldız F, Çoban S, Akıncı OF. Anovestibular fistula with imperforate anus in two adults. Ann Saudi Med 2008; 28:472-4.

10. Digray NC, Mengi Y, Goswamy HL, Thappa DR. Colorectal perforations in neonates with anorectal malformations. Pediatr Surg Int 2001; 17:42-4.

11. Rintala RJ. Congenital anorectal malformations: anything new? J Pediatr Gastroenterol Nutr 2009: 48 Suppl 2:S79-82.

12. Eltayeb AA. Delayed presentation of anorectal malformations: the possible associated morbidity and mortality. Pediatr Surg Int 2010; 26:801-6.

13. Lindley RM, Shawis RN, Roberts JP. Delays in the diagnosis of anorectal malformations are common and significantly increase serious early complications. Acta Paediatr 2006; 95:364-8.

14. Seidel HM, Rosenstein BJ, Pathak A, McKay W, eds. Primary care of the newborn. 4th ed. Philadelphia: Elsevier, 2006: 37-60.

15. Chirdan LB, Ameh EA. Neonatal intestinal perforation in a developing country. Ann Trop Paediatr 2001; 21:26-8. 